\title{
Cena
}

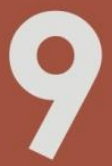

Dossiê Dança em Desdobramentos

PERIÓDICO DO PROGRAMA DE PÓS-GRADUAÇÃO EM ARTES CÊNICAS INSTITUTO DE ARTES | DEPARTAMENTO DE ARTE DRAMÁTICA UNIVERSIDADE FEDERAL DO RIO GRANDE DO SUL

\section{A (I)MOBILIDADE NA OBRA DE NIJINSKY: UMA AÇÃO INTEMPESTIVA}

\section{Sandra Meyer}

Professora do Curso de Licenciatura e Bacharelado em Teatro do Programa de Pós-Graduação em Teatro Mestrado e Doutorado - do Centro de Artes da Universidade do Estado de Santa Catarina (UDESC). Doutora em Artes, Comunicação e Semiótica (PUC/SP). 
RESUMO: $O$ artigo propõe uma reflexão sobre a obra de Vaslav Nijinsky (1890-1950) enquanto ação intempestiva, destacando a ação deste no seu tempo e a forma com que inseriu a dança noutro regime de temporalidade ao utilizar a imobilidade como estratégia de composição. Este artigo analisa a questão da imobilidade em duas das três marcantes obras de Nijinsky: $A$ tarde de um fauno [L'après-midi d'un faune, 1912] e Jogo [Jeux, 1913].

PALAVRAS-CHAVE: Dança; (I)mobilidade; Intempestivo.

ABSTRACT: The article proposes a reflection on the work of Vaslav Nijinsky (1890-1950) while intempestive action, highlighting the action of him in his time and the way that he inserted the dance in another regimen of temporality, using the immobility as composition strategy. This article analyses the question of the immobility in two of the three outstanding works of Nijinsky: "The afternoon of a faun" [L'après-midi d'un faune, 1912] and "Play" [Jeux, 1913].

KEYWORDS: Dance; (I)mmobility; Intempestive.

\section{INTRODUÇÃO}

"No começo era o movimento. Não havia repouso porque não havia paragem do movimento. O repouso era apenas uma imagem demasiado vasta daquilo que se movia, uma imagem infinitamente fatigada que afrouxava o movimento. Crescia-se para repousar, misturavam-se os mapas, reunia-se o espaço, unificava-se o tempo num presente que parecia estar em toda a parte, para sempre, ao mesmo tempo. Suspirava-se de alívio, pensava-se ter alcançado a imobilidade. Era possível enfim olhar a si próprio numa imagem apaziguadora de si e do mundo. Era esquecer o movimento que continuava em silêncio no fundo dos corpos. Microscopicamente. Ora, como se passaria do movimento ao repouso se não houvesse já movimento no repouso? No começo não havia pois começo" (GIL, 2004, p.13).

O convite para ministrar uma palestra no encontro "Loucura e Lucidez na obra de Nijinsky" "1 foi a chave para revisitar a obra de um dos artistas da dança mais marcantes do século XX. Enquanto um desdobramento daquela fala, 0 intuito deste artigo é o refletir sobre a obra de Vaslav Nijisnky (1890-1950) ${ }^{2}$

\footnotetext{
1 A palestra "A importância da obra de Nijinsky para a dança do século 20" ocorreu na Fundação Badesc, em Florianópolis, no dia 10 de março de 2011, com organização de Ana Luz.

${ }^{2}$ Nasceu em Kiev, na Ucrânia, em 28 de fevereiro de 1890, filho de Thomas Nijinsky (bailarino famoso em sua época) e Eleonora Bereda, aluna da Escola Estadual de Ballet de Varsóvia. Com 10 anos de idade foi aceito na Escola Imperial de Ballet de São Petersburgo. O primeiro papel de destaque veio aos 18 anos, em Le Pavillon d'Armide. Em 1908 é apresentado ao empresário e diretor de balé Sergei Diaghilev (1872-1929) e ingressa nos Ballets Russes, onde atuou como bailarino e coreógrafo.
} 
enquanto ação intempestiva, destacando a ação deste no seu tempo e a forma com que inseriu a dança noutro regime de temporalidade ao utilizar a imobilidade como estratégia de composição. E com isso, inaugurando um estado diferenciado de presença na dança. Este artigo analisa a questão da imobilidade em duas das três marcantes obras de Nijinsky: $A$ tarde de um fauno [L'après-midi d'un faune, 1912] e Jogo [Jeux, 1913].

A interrogação que finaliza a citação de Gil que abre este artigo é aqui retomada como um dispositivo: "Ora, como se passaria do movimento ao repouso se não houvesse já movimento no repouso?". A ideia de movimento remete inicialmente a algo que se desloca de um lugar a outro. Um corpo está em movimento quando, sobretudo, altera sua posição em relação a um referente no tempo. Em contraponto, a noção oposta, a de repouso ou de imobilidade, remeteria a um corpo ou objeto que mantém sua posição constante em relação a um referencial. Você está sentado num trem em movimento, mas em relação a este, estará em repouso. Neste sentido, movimento e repouso são conceitos relativos, pois dependem de um referencial.

O envolvimento motor no ato perceptivo colabora para o entendimento de uma noção que não é apenas figuração poética: há movimento no corpo que pausa. O vínculo entre percepção e movimento insere a paragem e a imobilidade no circuito da vida, considerando que a percepção simula a ação, e que a ação organiza a percepção. A presença de um corpo em sua aparente imobilidade deixa de ser uma atitude passiva para converter-se em uma atitude que instiga a percepção, que, em si mesma, provoca a emergência de um movimento, por mais invisível e sutil que seja. Uno à fala Gil, a de Alain Berthoz:

a percepção não é somente uma interpretação das mensagens sensoriais, ela é comandada pela ação, ela é uma simulação interna da ação, ela é julgamento e tomada de decisão, ela é antecipação das consequências da ação (BERTHOZ, 1997, p. 15).

Perceber já é, de alguma forma, agir, visto que não há, praticamente, nenhum dispositivo sensorial que não se encontre conectado a sinais motores. 
Nos escritos instigantes de seu diário ${ }^{3}$, Nijinsky revela o processo de criação de $A$ tarde de um fauno (L'après-midi d'un faune, 1912), destacando a questão da imobilidade.

Eliminei os movimentos sinuosos, indecisos, os gestos mal definidos, os percursos inúteis. Quero apenas o ritmo e os passos absolutamente indispensáveis. Enriquecerei o meu vocabulário, como fazem os poetas. A imobilidade? Serei o primeiro a utilizá-la de uma forma consciente. A estática é o equilíbrio de forças. A imobilidade pode acentuar o sentido da ação, do mesmo modo que o silêncio pode ser mais eficaz que as palavras. A dança, como as demais artes, é expressão da pessoa humana e dos seus pensamentos, deve ir para além das regras recebidas, é extensível até o infinito (apud SASPORTES, s/d, p. 52).

Diante de tais reflexões, parafraseio o filósofo italiano Giorgio Agamben (2009) ao indagar: como ser contemporâneo na relação com as figuras e documentos do passado? Neste caso, como podemos dialogar com a obra de Nijinsky cem anos após suas inventivas composições? Como podemos não somente reconhecer a contemporaneidade de sua obra, mas sermos contemporâneos a ela?

Em um texto esclarecedor ${ }^{4}$, Agamben problematiza o conceito de contemporâneo, aqui sintetizado. Para o autor a contemporaneidade seria uma relação singular com o próprio tempo, que adere a ele e ao mesmo tempo se distancia. Aqueles que coincidem muito facilmente a sua época, que aderem perfeitamente a aspectos de seu tempo não seriam exatamente contemporâneos. A relação singular com o próprio tempo pressupõe, paradoxalmente, aderência, dissociação e anacronismo. O olhar fixo no seu tempo não seria para nele perceber as luzes que refletem, mas as brechas que enunciam a obscuridade. Ou seja, perceber algo que nos interpela no "escuro" de nosso tempo. É por isso que Agamben (2009) afirma que o contemporâneo é o intempestivo.

\footnotetext{
${ }^{3}$ O Diário de Nijinsky, organizado por Romola Nijinsky, reúne as anotações feitas por Vaslav Nijinsky durante sua estada em Saint-Moritz, cidade suíça onde se abrigou em 1918 com sua mulher, Romola, para esperar o fim da I ${ }^{\mathrm{a}}$ Guerra Mundial. Ele escreveu obsessivamente, não permitindo que ninguém o lesse. Esses textos (escritos originalmente em russo e polonês) foram reencontrados apenas em 1934, casualmente, entre os cadernos escolares de sua filha.

4 "O que é o Contemporâneo? e outros ensaios". Chapecó: Editora Argos, 2009.
} 
Nijinsky viveu o seu tempo e, ao mesmo tempo, soube interpelá-lo, com sua arte absolutamente coerente com sua complexa existência. Assim como o filósofo alemão Friedrich Nietzsche, de quem era leitor, que construiu sua filosofia por meio de uma atividade crítica perante a história, atuando nela de maneira intempestiva - "ou seja, contra o tempo, e com isso, no tempo e, esperemos, em favor de um tempo vindouro" (NIETZSCHE, 2003, p.7), Nijinsky acionou o intempestivo, criando novos planos de composição para a dança. No momento em que o balé parecia esvaziar-se, frente ao surgimento de novos preceitos da dança moderna, ele não rejeitou essa tradição clássica, como ocorreu com Isadora Duncan (1877-1927) e Mary Wigman (1886-1973). Soube criar uma nova abordagem que reescreveu criticamente a gramática estabelecida historicamente por inúmeros mestres de balé.

De fato, é isso que quer dizer intempestivo, essa ação vital movida por um pathos afirmativo que se lança contra o tempo presente, numa oposição tanto teórica quanto prática a tudo aquilo que a época glorifica; a partir, portanto, de uma perspectiva que não é meramente histórica nem muito menos teleológica; simplesmente, intempestiva. Sem dúvida, ainda de certa maneira temporal, mas tão apenas porque investe seus esforços em prol de um novo tempo e uma outra época (PETER PÁL PELBART apud MEDEIROS, 2010, p.17).

Grande parte da poética da dança no século $X X$ regeu-se a partir de determinados princípios de organização cinética e expressiva do corpo. Os princípios de sequência, que auxilia o movimento a se propagar pelas partes do corpo de forma fluida, de oposição, que resulta em uma dinâmica de partes do corpo que se movem simultaneamente em direções opostas e de correspondência, que auxilia a interconexão entre o físico, o mental e o espiritual propostos por François Delsarte (1811-1871); e as proposições sobre o peso, o corpo, o espaço, o tempo e as dinâmicas do movimento elaborados por Rudolf Laban (1879-1958) são exemplos incontestáveis dessa perspectiva eminentemente cinética. Contudo, a ideia de romper com o fluxo do movimento, considerando as micro percepções que a suspensão do contínuo e a imobilidade do corpo propicia pode ser observada avant la lettre nas obras de Nijinsky.

Vale ressaltar que muitos artistas de dança contemporânea, ou melhor, artistas contemporâneos da dança, nos últimos anos, vêm revendo certas 
categorias universais, não somente por meio da negação da prática virtuosa e espetacular do movimento dançado, ou de certos padrões corporais estabelecidos pela história da dança, mas por meio de interpelações sobre o próprio conceito de dança e da associação direta desta com o movimento. Expressiva parcela da produção européia e brasileira converge em sua crítica à herança ontológica da modernidade, cuja pulsão pelo movimento do corpo e sua energia cinética (harmonia, ritmo, dinâmica) organiza os modos de representação na dança (LEPECKI, 2006). Os atos imóveis (still acts) ${ }^{5}$, presentes em trabalhos de artistas como de Jérome Bell, La Ribot, Marta Soares e Michelline Torres desafiam o aparato sensorial e cognitivo, iniciando o sujeito noutra relação com a temporalidade, com certos ritmos corporais préestabelecidos pela dança e com experiências acerca da percepção e presença do artista e do espectador.

Já nos anos 1960, Steve Paxton, nas investigações que geraram a Improvisação de Contato, propunha aos estudantes que percebessem as forças elementares do corpo, as que nos permitem permanecer de pé sem um movimento aparente, revelando uma quantidade de movimentos ínfimos, alguns microscópicos, e que fazem o corpo esboçar incansavelmente uma "pequena dança" [small dance], fonte primeira de todo o movimento humano (apud GIL, 2001, p.134).

Esta perspectiva insere a dança num determinado campo ético e político. Os gestos lentos, a suspensão e dilatação do tempo seriam possíveis atos de resistência a um pretenso fluxo sem entraves ou sem tensão que as políticas dominantes insistem em veicular. A imobilidade pode se constituir como um ato de resistência que liberta a dança da "fatalidade do movimento", expondo um outro modo de presença (GOUMARRE, 2004). Vejamos como Nijinsky "acentuou o sentido da ação" por meio da (i)mobilidade.

\footnotetext{
${ }^{5}$ Conceito desenvolvido por Nadia Seremetakis, revisitado por André Lepecki (2005) em sua análise da obra de Jérôme Bel.
} 


\section{A TARDE DE UM FAUNO}

Aos vinte e dois anos, a primeira coreografia: $A$ tarde de um fauno [L'après-midi d'un faune, 1912], com partitura musical escrita em 1894 por Claude Debussy (1862-1918) ${ }^{6}$ à sombra do poema do escritor e poeta simbolista francês Stéphane Mallarmé (1842-1898). Publicado em 1876, o poema L'après-midi d'un faune descreve a experiência de um fauno logo após acordar de seu sono vespertino, quando ele relembra as aventuras sensuais que tivera pela manhã, junto a ninfas, numa espécie de monólogo de um sonho.

Serge Diaguilev (1872-1929), o diretor dos Ballets Russes ${ }^{7}$, costumava acompanhar Nijinsky a museus europeus para que o bailarino pudesse conhecer a iconografia de civilizações diversas. Desta vez foi o cenógrafo e pintor russo Léon Bakst (1866-1924) o encarregado de instruir Nijinsky sobre as diferenças entre a escultura grega arcaica e a helenística, posto que "A tarde de um fauno" proporia uma visão da Grécia. Desta vez o bailarino teria se detido mais tempo nas galerias de arte egípcia do Louvre, o célebre museu francês. A estada como bailarino no Teatro Marinsky, na Rússia, parece o ter convencido de que era possível ir além das formas aparentes do estilo orientalista e estudar as proporções e o modo de representação da arte antiga (KIRSTEIN, 1975).

Outros coreógrafos antes de Nijinsky utilizaram referências da arte egípcia em suas criações, como os grandes mestres Marius Petipa (18181910) e Michel Fokine (1880-1942). Nijinsky, contudo, utilizaria não como símbolo de um exotismo em voga na Europa, que se dava nos efeitos de cenografia e figurino emoldurando corpos que emitiam os códigos da dança clássica aliado a certos gestos das culturas ancestrais, mas como elemento de reconstrução coreográfica. Numa operação conceitual sofisticada, ele inventa

\footnotetext{
${ }^{6}$ Debussy é considerado o pai da música moderna, apesar de ter vivido no tempo da "belle époque". Sua obra libertou-se dos cânones tradicionais, das repetições e das cadências rítmicas, tendo dado extraordinária importância aos acordes isolados, aos timbres, às pausas, visto em obras como Prèlude à l'Après-Midi d'un Faune (1894) e La Mer (1904).

${ }^{7}$ O Ballets Russes foi uma companhia emigrada da Rússia, com sede em Paris, dirigida por Serge Diaghilev, cuja atividade manteve-se de 1909 a 1929. Grandes nomes da arte contribuíram para tornar a Cia célebre, dentre eles Vaslav Nijinsky.
} 
um alfabeto que atravessa a estrutura do balé, repercutindo numa outra sensibilidade e sensualidade para a dança.

A tarde de um fauno representa "[...] esteticamente um nova dialética de contrastes: movimento de encontro à música, ação estática de encontro à turbulência sinfônica, extrema angularidade ao invés de sinuosas curvaturas" (KIRSTEIN, 1975, p.125) $)^{8}$. Nijinsky considerou mais o caminhar do que o dançar. Movimentos contidos, com pouca projeção e extensão no espaço. Nijinsky não criou uma personagem ou um maneirismo teatral a partir da arte grega ou egípcia. Às custas de intermináveis ensaios com os bailarinos do Ballets Russes criou uma proposição que fugia das cinco posições dos pés, dos portées e das posições en dehors, próprias da gramática do balé.

A percepção de Nijinsky em relação ao passado diferencia-se de outras importantes investidas de coreógrafos em sua época em direção a culturas antigas, considerando que o olhar para outras civilizações, especialmente para um certo "oriente" imaginado, foi um dos fatores propulsores da dança moderna no início do século XX, a exemplo de Isadora Duncan, em sua conexão com a Grécia, e Ruth Saint-Denis, em seu interesse pelo Egito e Índia. Como afirma Agamben (2009, p.69) "somente quem percebe no mais moderno e recente os índices e as assinaturas do arcaico pode dele ser contemporâneo". O arcaico, em sua etimologia, significa estar próximo à origem [arké], o que não significa um passado distante e estanque, mas contemporâneo ao devir histórico, e que não cessa de operar neste ${ }^{9}$.

As posturas criadas em Fauno se relacionam com o princípio de baixo relevo. Os corpos em perfil, tal como na lei da frontalidade, presente especialmente na arte egípcia, impõem um forte componente estático, de uma imobilidade solene. Não é a noção de perspectiva, em seus níveis simulados de profundidade, que determina a dimensão simbólica. Nijinsky favoreceu a aparição linear na percepção visual do espectador escamoteando a percepção do volume do corpo por meio da rotação rápida deste. O público não

\footnotetext{
${ }^{8}$ Aesthetically, Faune presented a new dialectic of contrasts: movement against music, static action against symphonic turbulence, extreme angularity of decoration against luscious curvature.

${ }_{9}^{9}$ Agamben (2009) cita o exemplo do embrião que continua a agir nos tecidos do organismo maduro e a criança na vida psíquica do adulto.
} 
visualizava o rosto e o corpo do bailarino de frente. As posições dos pés e pernas indicam a direção do movimento, os ombros e os braços apontam para o público e o olhar aponta para o movimento que seguirá. A ideia de um movimento livre do tronco e dos braços descobertos por Isadora Duncan se incorpora de outra forma na proposição de Nijisnky. Ele condensa esta nova liberdade do tronco num princípio coreográfico que busca um efeito cênico similar a um relevo, ou seja, de uma representação em duas dimensões.

Os deslocamentos dos bailarinos no sentido das laterais do palco cria uma outra concepção de frontalidade. Nijinsky revisita em Fauno a lei da frontalidade não somente na posição do tronco, nos gestos das mãos e no perfil enigmático, mas na disposição espacial. Os bailarinos se movimentam em faixas horizontais, desconhecendo as regras de perspectiva entre figura e fundo, tão caras ao balé, arte de gênese renascentista. Jeschke e Hutchinson (1992, p.88) afirmam que Nijinsky cria para seus dançarinos um plano de ações fechado, o que o teatro nomeia como a quarta parede, sendo que esta não existia na cena da dança clássica. Ele cria um espaço cênico fechado, mas, ao mesmo tempo, o espectador decide se e como participa da ação cênica: "uma ideia libertadora e revolucionária que transgride e confronta uma tradição, a do balé, fundada sobre a edificação e o divertissement (JESCHKE; HUTCHINSON, 1992, p.88).

\section{JOGOS DE ABSTRAÇÃO DO DESEJO}

No momento em que começava a coreografar Jogo [Jeux], Nijinsky estava compondo A Sagração da Primavera [Le sacre du printemps] e lidando com a pressão da repercussão da estréia de $F_{a u n o}{ }^{10}$. O próprio artista reconhece as limitações impostas pelo contexto. Não teria tido o tempo necessário para compor (NIJINSKY, 1985, p. 243). Diaguilev solicitou ao pintor Jacques-Émile Blanche sugerir um arquétipo para Nijisnsky que pudesse canonizá-lo como um "homem moderno". Blanche escolheu a imagem do esportista, a partir de um olhar semi-heróico. Contudo, em seu diário, Nijinsky

${ }^{10}$ A estréia de L'après-midi d'un faune ocorreu em 29 de maio de 1912, no Théâtre du Châtelet, em Paris. A coreografia mostrava uma sensualidade impensável para a época e rompia com os padrões do balé clássico. A simulação de um orgasmo na cena final entrou para a história como um dos maiores escândalos da dança. 
revela seu próprio ponto de vista, com forte componente emocional. Ele declararia que estaria apaixonado na época pela bailarina russa Tamara Karsavina (1885-1978), sua partner nos Ballets Russes, e que ela não teria correspondido a sua afetividade:

Compus este balé sobre o desejo. Não fui bem sucedido neste balé, porque não o sentia. Havia começado bem mas me apressaram e não o conclui. Nesse balé vê-se o desejo de três jovens. Aos vinte e dois anos eu compreendi a vida. Compus sozinho esse balé. Diaguilev e Bakst me ajudaram a escrever o tema do balé, pois Debussy exigia o tema no papel. Pedi ajuda e eles escreveram o balé. [...]. Alegra-me Diaguilev dizer que imaginou os temas do Fauno e de Jogos, pois compus esses balés sob a impressão de minha vida com ele. O Fauno sou eu, e Jogos é a vida com que Diaguilev sonhava. Ele queria amar dois garotos ao mesmo tempo, e queria que esses garotos o amassem. Os dois garotos são as duas moças e Diaguilev o rapaz. Disfarcei esses personagens de propósito, pois eu queria que as pessoas sentissem repulsa. Eu sentia repulsa por isso não pude terminar o balé (NIJINSKY, 1985, p. 243).

Uma peça diferenciada. Um jogo de sedução entre duas garotas (Ludmilla Schollar e Tamara Karsavina) e um rapaz (Nijinsky) em movimentos ritmados, sem a presença de um corpo de baile, tampouco piruetas, entrechats ou fouteés. Lincoln Kirstein (1975) enfatiza que as experimentações desta coreografia favoreceram uma despersonalização do movimento, uma variante do idioma acadêmico, agora em outra direção daquela investigada em "Fauno".

Em "Jogo" não há uma narrativa, mas somente uma relação de corpos numa situação psicológica complexa. A atmosfera de distúrbio entre as duas garotas e o rapaz fala de uma intimidade tácita, contudo, não revela facilmente a questão de cunho pessoal relatada por Nijinsky. A inventividade reside na formalização da construção coreográfica, numa aproximação com a arte abstrata iniciada no início do século XX. Jogo era o primeiro tema dos Balles Russes não atrelado a um libreto. Ou seja, o primeiro balé a abordar um tema "moderno" (tanto o esporte como a relação amorosa triangular) e a incorporar movimentos, cenário e figurinos do cotidiano, tais como uma raquete de tênis, vestidos, calça, gravata e camisa social (KIRSTEIN, 1975, p. 137).

Riviére (apud SASPORTES, s/d, p. 101-102) critica Fokine por manter o conceito de expressão herdado de Noverre, ou seja, a dança como uma arte de imitação, que deveria ilustrar os sinais de um comportamento emocional. Já 
nas obras de Nijinsky o movimento deferiria do que se intitularia como expressivo, pois não falaria de outra coisa que não de si próprio, a exemplo de Jogo. A expressão seria um objeto pré-existente à dança, e que esta tornaria visível. "Na dança de Nijinsky, o rosto não tem um papel autônomo; prolonga o corpo; é apenas a sua flor. Para começar, é o corpo que fala" (apud SASPORTES, s/d, p.101-102).

Em Jogo, os braços não são curvos como os do balé. As mãos são levemente flexionadas no punho, dedos fechados como se sustentassem uma raquete. Poses sequenciadas em staccato, formas angulares, pés e joelhos flexionadas. O músico Claude Debussy, compositor de Jeux, tinha ressalvas quanto à concepção do coreógrafo:

Nijinsky criava triplos colchetes com seus pés, com seus braços, então, quase que paralisado, permanecia enfurecido deixando o som deslizar. Isto é terrível. É como Dalcroze que, para mim, é um dos piores inimigos da música, imagine o que este sistema pode provocar de perigo na mente de um jovem bárbaro como Nijinsky (apud KIRSTEIN, 1975, p. 138). ${ }^{11}$

Percebe-se claramente a crítica ao sistema elaborado pelo músico suíço Emile Jacques Dalcroze (1869-1950), além da desconfiança em relação ao repertório musical do jovem coreógrafo $^{12}$. Debussy reconhece também similaridades entre os movimentos criados por Nijinsky e os padrões corporais de pacientes com patologias mentais. Ele escreveu: "Ele dançou como se fosse golpeado de repente pela paralisia em um lado" (apud OSTWALD, 1991, p.63) ${ }^{13}$. Peter Ostwald (1991) reconhece igualmente que os movimentos mais grotescos podem ter derivado, de forma consciente ou não, das memórias de movimentos patológicos observados por Nijinsky em suas visitas ao seu irmão em hospitais psiquiátricos, pois este sofria também de doença mental, na época denominada Neurastenia.

\footnotetext{
${ }^{11}$ Debussy did not like Jeux a bit, for it " gave Nijinsky's perverse genius a chance of indulging in a peculiar kind of mathematics. This fellow adds up triple crochets with his feet, checks them on his arms, then suddenly, half paralysed, he stands angrily letting the sound slip by. It's awful. It's even Dalcrozian - for I take Monsieur Dalcroze as one of worst enemies of music and you can imagine what damage his system can create in the mind of a young barbarian like Nijinsky". (Apud Kirstein, 1975, p. 138).

${ }_{12}$ Nijinsky aproximou-se deste sistema por conta do processo complexo de composição de Sagração da Primavera. Ele abdicou de dançar e teve o suporte de Marie Rambert (1888-1982) na utilização dos princípios do sistema de Dalcroze. Formada em Euritimia pela escola de Dalcroze, foi convidada a integrar os Ballets Russes como professora.

${ }^{13} \mathrm{He}$ danced as if suddenly struck by paralysis on one side.
} 
Nijinsky rompe com o fluxo contínuo do movimento, ao valer-se do modo staccato ou "destacado/separado", que designa um tipo de fraseio no qual as notas e os motivos das frases musicais são executadas com suspensões entre elas, ficando as notas com curta duração. É uma técnica de execução instrumental ou vocal que se opõe ao legato, ou seja "ligado" em uma "ligadura de expressão". O staccato, quando ouvimos, soa como de menos duração, já o ligato traduz-se na forma suave de ligar dois ou mais sons. Se no canto o legato requer uma expiração controlada e contínua, no staccato pressupõe um tipo de emissão contrária ao "legato", em que os sons resultam destacados através da saída do fluxo de ar (expiração) por meio de impulsos e descontinuidades ${ }^{14}$. Parece ser esta a lógica presente em Jogo.

A imobilidade perpassou não somente a obra de Nijinsky, mas ressoou no imaginário de Isadora Duncan. Em uma sala de ensaio, imóvel, ela buscava descobrir o princípio do movimento tocando com as mãos a região do plexo solar. Ela escreveu que permanecia "cerca de duas horas esperando, imóvel, o nascimento de um gesto" (apud GOUMARRE, 2004, p.52). Ou seja, ela fez da imobilidade uma atitude necessária para que um gesto pudesse surgir. "A imobilidade como um preâmbulo do movimento" (GOUMARRE, 2004, p.52). Vale ressaltar que a imobilidade estava no imaginário cênico da época, por meio da formação de cenas em um conjunto, tal como das estátuas vivas [living statues], também chamadas de poses de estátuas [statue-posing], equivalentes aos "quadros vivos" [tableaux vivants], tradicionais nos teatros de New York no final do século XIX, que por sua vez seguiam o modelo da esculturas gregas. Isadora foi provavelmente contaminada por essa estratégia de expressão, "que remetia a uma ideia de absoluta calma e repouso de uma alma imortal" (DALY, 2002, p.125). Nijisnky imprimiu outro sentido à imobilidade, trazendo à tona um lado mais obscuro da condição humana.

Valentine Gross (apud KIRSTEIN, 1975, p.137) escreve na época sobre os esforços do genial bailarino em relação aos da jovem escola de arte moderna "cujo objetivo não é a reprodução servil de aspectos da natureza mas a descoberta da sua tradução idealizada, mas pessoal”. Jogo ficaria à sombra

\footnotetext{
${ }^{14}$ Acesso em 01/07/11. Fonte: http://pt.shvoong.com/entertainment/music/1690527-segredosda-voz-parâmetros-legato/\#ixzz1NhsMfUFn.
} 
de A tarde de um fauno e da Sagração da Primavera [Le Sacre Du Printemps, 1913], a terceira e mais célebre obra de Nijinsky. Contudo, as duas obras de Nijinsky com músicas de Debussy representaram dois grandes saltos inventivos da dança no século XX.

\section{A ÚLTIMA DANÇA}

No início do inverno de 1918, a $1^{\text {a }}$ Guerra recém eclodia na Europa enquanto Nijinsky lia Ecce Homo ${ }^{15}$, uma das obras mais controversas de Nietzsche, publicada em meio ao agravamento da doença e do transtorno mental do filósofo. A intenção de Nietzsche ao deixar esta última obra, pelas suas próprias palavras, era de não ser confundido ou mal compreendido. Tinha receio de ser "santificado" ou idolatrado: "Eu sou um aprendiz do filósofo Dionísio, e faço mais gosto em ser tomado como sátiro do que santo" (apud KIRSTEIN, 1975, p.148).

A mente de Nijinsky se tornava cada vez mais complexa. Os seus diários revelam o desejo íntimo de ser sentido e compreendido, muito mais pela sensação e sentimento, e até mesmo pela razão, mas nunca pelo intelectualismo ou inteligência (NIJINSKY,1885). O pensamento seria um impedimento para a compreensão. Nietzsche não acreditava em um deus que não dançasse. Nijinsky via a si mesmo ora como deus ora como homem. Ao promulgar a morte de Deus, Nietzsche estaria proclamando que o conceito de uma deidade teria sido suplantado pelo de uma consciência criativa do sujeito, provocando uma ascese do homem frente à figura de Deus. Nijinsky declararia: "Gosto de Nietzsche, mas ele não me compreenderá, pois pensa".

As pessoas acham que eu vou ficar louco, pois acham que eu vou perder a cabeça. Foi Nietzsche quem perdeu a cabeça, pois pensava. Eu não penso, por isso não perderei a cabeça. Tenho a cabeça sólida, e, dentro da minha cabeça, também é sólido. Eu ficava de pé sobre a cabeça no balé Shéhérazade, no qual devia representar um animal ferido. Eu representava bem o animal, por isso o público me compreendia. Agora, representarei o sentimento, e o público me compreenderá (NIJINSKY, 1985, p.48).

\footnotetext{
${ }^{15}$ Em português, a frase significa "Eis o homem". De acordo com o evangelho seriam as palavras que Pôncio Pilatos teria dito, em latim, ao apresentar Jesus Cristo aos judeus.
} 
Nietzsche escolheu a dança como metáfora da leveza e da dinâmica do pensamento. A agilidade do dançarino se assemelharia à vida vivida com o espírito de uma criança. Nietzsche enuncia uma dança sem códigos determinantes, mas sim uma ação que é desintegradora de códigos e do senso comum: "Para que arte seja de fato vital e ofereça ao indivíduo uma experiência única e totalizante sobre a vida ela deve ter a energia anterior ao do regramento trágico, ela deve ser, em suma, dionisíaca" (NIETZSCHE apud KIRSTEIN, 1975, p.148). A dança imaginada pelo filósofo seria talvez mais próxima da última performance de Nijinsky do que das exuberantes apresentações do bailarino nos Ballets Russes, coreografado por Fokine.

Em 19 de janeiro de 1919, aos 29 anos, Nijinsky dançou publicamente pela última vez, num espetáculo beneficente num dos salões do Hotel Suvretta de Saint-Moritz, nos Alpes suíços. Ante uma platéia de turistas, aristocratas e novos ricos apresenta o que sua esposa Romola denominou como "a dança da vida contra a morte" (NIJINSKY, 1985, p. 14) ${ }^{16}$. Ao invés de divertir-se com a célebre destreza técnica do bailarino, o público deparou-se com uma dança trágica que evocava os horrores da guerra que devastara a Europa nos últimos quatro anos. Antes mesmo de Mary Wigman dançar Monument aux morts, em 1930, um monumento vivo à memória dos mortos da grande guerra, Nijisnky incorporava em sua dança o seu drama pessoal e também o contexto social. Quando Nijinsky dança sua própria dança, uma dança "divina", atravessado por forças interiores e exteriores, em busca de uma superação, aproxima-se, de certa forma, ao pensamento nietzschiano.

$\mathrm{Na}$ primeira parte de seu diário ele descreve os momentos que antecedem a esta última dança: "[...] vou dançar quando tudo tiver se acalmado, quero dançar porque sinto, e não porque estão me esperando" (NIJINSKY, 1985, p. 28).

Dancei coisas assustadoras. Eles tiveram medo de mim, por isso acharam que eu queria matá-los. Eu não queria matar ninguém. [...] o público não gostou de mim, pois quis ir embora, então comecei a representar coisas engraçadas. Eu ria em

\footnotetext{
${ }^{16}$ A tentativa de Nijinsky de montar seu próprio grupo sucumbiu 16 dias após o início. Durante a I ${ }^{\mathrm{a}}$ Guerra Mundial esteve internado em um campo de concentração na Hungria, de onde só saiu em 1916, por intercessão de Diaghilev.
} 
minha dança. O público também ria na dança.[..] eu quis continuar dançando, mas Deus me disse: Chega. Então eu parei (NIJINSKY, 1985, p. 28).

Sem os adornos, cenografia e aparato da arte total idealizada por Diaguilev no período dos Ballets Russes, em um salão de um hotel Nijinsky evoca uma dança "pobre", onde o corpo e a carne visceralmente expunham paradoxalmente as mazelas e o dilaceramento de uma civilização pós-guerra, bem como expunham a frágil e conturbada condição humana do dançarino, anterior à internação em uma instituição psiquiátrica que o afastaria definitivamente dos palcos e do convívio social, até a sua morte, em 1950.

Lembremos novamente da noção do contemporâneo como o intempestivo, ou seja, o que não cessa de nos interpelar. A ação intempestiva provocada pelas criações de Nijinsky em Fauno e Jogo se apresenta como uma força capaz de se deslocar no tempo e no espaço, se tornando extemporânea. O pensamento intempestivo atua para além dos preconceitos e valores de seu tempo, traçando, indefinidamente, novas perspectivas.

Jaques Ruviére (apud KIRSTEIN, 1975, p. 143), ao escrever uma crítica sobre a obra de Nijinsky, questiona o papel do coreógrafo estabelecendo uma relação com o tempo:

O autor de um balé não é nem o poeta, nem o decorador, nem mesmo o compositor. No mesmo momento em que ganha consciência dos movimentos do bailarino, entende que a beleza não se mede através da perfeição da pose onde começa e acaba um enchainement, mas no percurso do bailarino no tempo. Isto é, nessa trajetória pulsante que a mão do pintor não poderá fixar. A dança não é um perfil: é um caminho a nossa frente.

\section{REFERÊNCIAS BIBLIOGRÁFICAS}

AGAMBEN, Giorgio. O que é o Contemporâneo? e outros ensaios. Chapecó: Editora Argos, 2009.

BERTHOZ, Alain. Les sens du mouvement. Paris: Éditions Odille Jacob, 1997. 
DALY, Ann. Done into Dance. Isadora Duncan in America. Middletown: Wesleyan University Press, 2002.

GIL, José. Movimento Total: O Corpo e a Dança. São Paulo: lluminuras, 2004. KIRSTEIN, Lincoln. Nijinsky Dancing. New York: Alfred A. Knopf Inc., 1975.

GOUMARRE, Laurent. Die Another Day In: La Ribot. Paris: Merz \& Centre National de la danse. Parcours d'artistes, 2004.

JESCHKE, Claudia; HUTCHINSON GUEST, Ann. Waslaw Nijinsky, chorégraphe du faune In: STANCIU-REISS, Françoise; POURVOYER, JeanMichel (org.). Ecrits sur Nijinsky. La recherche en danse. Paris: Éditions Chiron, 1992.

LEPECKI, André. Desfazendo a fantasia do sujeito (dançante): 'Still acts' em The Last Performance de Jérôme Bel. In: PEREIRA, Roberto; SOTER, Silvia (org.) Lições de Dança 5. Rio de Janeiro: UniverCidade, 2005.

MEDEIROS, L. F. Rego de. O filósofo e o Intempestivo. Dissertação defendida no Programa de Filosofia da UFRGS, 2010.

NIETZSCHE, F. Segunda consideração intempestiva: Da utilidade e desvantagem da história para a vida. Rio de Janeiro: Relume Dumará, 2003.

NIJINSKY, Romola (org.) O diário de Nijinsky. Rio de Janeiro: Rocco, 1985.

OSTWALD, Peter. Vaslav Nijinsky. A leap into madness. New York: Lyle Stuart Book, 1991.

SASPORTES, José. Pensar a Dança. A reflexão estética de Mallarmé a Cocteau. Brasília: Imprensa Nacional, s/d. 